\title{
INVESTIGACIONES
}

de HISTORIA ECONÓMICA

2008, otoño, número 12. Pp. 141 a 168

\section{Cambio político, instituciones y empresas ferroviarias en España (1918-1936)}

\section{Political change, institutions and railway companies in Spain (1918-1936)}

\author{
PEDRO PABLO ORTÚÑEZ GOICOLEA \\ Universidad de Valladolid
}

\begin{abstract}
RESUMEN
El texto muestra cómo el Estado modificó su posición respecto al sector ferroviario y a las empresas concesionarias después de la I

Guerra Mundial, de acuerdo con los principios surgidos entonces sobre la intervención de los gobiernos en las actividades económicas. Posteriormente, la necesidad de las empresas ferroviarias españolas de contar con el Estado para que éste aprobara una elevación de tarifas, le hizo de nuevo fuerte y le permitió pasar de regular a intervenir en el sector y en las empresas, hasta llegar a la nacionalización de las mismas en 1941. Esta modificación del escenario para las dos partes llevó a crear instituciones y organizaciones que articularan esa intervención.

PALABRAS CLAVE: Instituciones y Organizaciones, Regulación de sectores públicos, Transportes y Estado, Historia de empresas ferroviarias, España Códigos JEL: N24, N44, N74

\section{ABSTRACT}

This paper shows how the State changed its attitude towards the railway industry and the concessionaire firms after the First World War, according to the new arising principles on public intervention in the economy. Spanish railway companies needed to keep in good terms with the State in order to get their fees increased, so the State assumed a more dominant role. It shifted from regulating to intervening in the industry and in the firms to finally end up by nationalizing the companies in 1941. This change in the scene for both sides led to the creation of institutions to deal with that intervention.

KEY WORDS: Institutions and Organizations, Public sector regulation, Transportation and State, History of railway companies, Spain

JEL Codes: N24, N44, N74
\end{abstract}




\section{Introducción ${ }^{1}$}

Las mayores empresas ferroviarias españolas (Norte y MZA), que fueron entre 1918 y 1936 las empresas más grandes del país ${ }^{2}$, desarrollaron la fase final de sus concesiones en un marco institucional cambiante. En este período, España asistió al final de la Monarquía liberal, a una Dictadura militar y a su II República. La inestabilidad política, sobre todo en 1918-1923 y 1930-1936, dificultó las respuestas de los gobiernos a muchos de los problemas planteados, entre otros el ferroviario ${ }^{3}$.

Las dificultades del Estado se acentuaron por las deficiencias que presentaban el sistema fiscal y la Hacienda Pública, antiguo problema que, junto con las ideas liberales dominantes, causó que determinadas actividades económicas se confiaran en régimen de concesión a empresarios privados. Había sido lugar común entre los liberales decimonónicos que, si se quería disponer de un sistema ferroviario, el Estado lo más que podía hacer era crear un marco de incentivos para que la iniciativa privada construyera y explotara la red ${ }^{4}$. En los años que abarca este estudio, el Estado se planteó la necesidad de recuperar algunas de las competencias abandonadas desde el establecimiento de la primera ley general de ferrocarriles en 1855. El Estado, el regulador, habría sido capturado en sus intereses - al menos parcialmentepor las grandes compañías ferroviarias, los regulados, convirtiéndose así los distintos gobiernos en defensores de los intereses de las grandes compañías ${ }^{5}$.

[Fecha de recepción del original, octubre de 2007. Versión definitiva, febrero de 2008]

1 Agradezco a Marta de Andrés los interrogantes y correcciones que realizó a una primera redacción y que contribuyeron a perfilar mejor algunas ideas. Asimismo, a Javier Vidal, al Consejo de Redacción de IHE y a los tres evaluadores anónimos por la calidad de sus comentarios y sugerencias.

$2 \quad$ Carreras y Tafunell (1997), pp. 283-284.

3 Tusell y Queipo de Llano (2001), pp. 343-344, hablan de la "catarata de conflictos" a los que se enfrentaron los gobiernos entre 1917 y 1923 — que no desapareció para sus sucesores-y cómo "con sólo la excepción de Portugal y Yugoslavia, España tuvo el ejecutivo más inestable del período de entreguerras anterior a la crisis de 1929". Asimismo, Jordana y Ramió (2005), p. 1.001.

4 Ortúñez y Vidal (2000). En consonancia con la debilidad de las funciones que el Estado español desempeñaba en el sector ferroviario - lo que no significa que su esfuerzo financiero hasta entonces hubiera sido menor (Artola, 1978; y Herranz, 2004)—, estaba la insignificante presencia que éste tenía en los organigramas del Ministerio de Fomento. El Ministerio contaba con una Sección de Ferrocarriles dentro de la Dirección General de Obras Públicas y una mínima partida presupuestaria destinada a financiar gastos administrativos derivados de la supervisión de las empresas privadas (Ortúñez, 2002).

5 Proceso todavía no investigado en profundidad debido a las dificultades existentes para conocer las tarifas que realmente percibieron las empresas ferroviarias, cuestión esencial para valorar en su justo término el alcance de la captura del Estado. No es éste, empero, el objeto de análisis del presente trabajo. Comín et al. (1998), t. 1, p. 219, refiriéndose a la política tarifaria de las empresas antes de la Gran Guerra, señalan que "era el Estado el que debía haber regulado las tarifas para bajarlas, compensando las pérdidas de las compañías con mayores subvenciones. Pero las intervenciones del Estado durante la Restauración no se caracterizaron por su ortodoxia económica ni por atender a los intereses generales de los consumidores". Véanse, asimismo, Ortúñez y Vidal (2004) y Artola (1978). 
Las relaciones entre el Estado y las compañías ferroviarias fueron, desde el origen de este sistema de transporte, muy estrechas y extremadamente complejas, tanto en España como en el resto de los países europeos. Estas relaciones, empero, se alteraron entre 1918 y 1936, en buena medida a consecuencia del también mudable marco institucional. Diversos factores perturbaron a cada una de las partes en liza, entre otros la profunda crisis financiera en que cayeron las empresas concesionarias a partir de la I Guerra Mundial, y que fue el detonante de las transformaciones de la política estatal para la regulación del sector y la intervención en las compañías. Podríamos deducir, por tanto, que el Estado se vio impelido a actuar por las circunstancias, además de por las propias empresas. No obstante, al tratarse de cuestiones que por su propia naturaleza son cambiantes, resulta complejo estudiar dicho conflicto en el tiempo; de ahí el interés de identificar, primero, cuáles fueron los intereses de las partes implicadas en él. El Estado, sin pretender la explotación directa de la red ferroviaria, sí trató de recuperar el control sobre un servicio público esencial, y para ello procuró regular el sector e intervenir en la gestión de las compañías. Éstas, por su parte, emplearon todo tipo de argumentos en el intento de retrasar o hacer desaparecer cualquier medida considerada inconveniente.

A la altura de 1918, Cambó acertó a distinguir una doble vertiente del problema: por un lado, las que denominó dificultades coyunturales de las empresas —en su opinión producidas por la guerra-; y, por otro, las estructurales del propio sistema de explotación. El conflicto de intereses surgirá al intentar resolver unas y otras, y esta clasificación y forma de entender el problema estarán presentes desde entonces. Las "dificultades estructurales" de la explotación se asociaban al fracaso del sistema de concesiones y a la complejidad de la estructura de la red que había supuesto la existencia de muchas pequeñas compañías inviables; se requería una reordenación del sector y su reunificación, y para ello el Estado debía actuar, en principio, por la vía prevista en la legislación de 1855: el rescate. Todas las decisiones en este sentido fracasaron hasta 1941, aunque puede hacerse la excepción, parcial, con el Estatuto de 1924, como se verá más adelante. Los condicionantes del Estado para culminar con éxito estas iniciativas, llevaron a la vía intermedia de remediar las "dificultades coyunturales" para no colapsar la economía nacional con la paralización del transporte y seguir prestando ese servicio público.

Cómo solucionar estos problemas coyunturales también enfrentó a Estado y empresas. Para las últimas, la salida fue siempre el aumento de las tarifas máximas legales; decisión que, sin embargo, se postergaba como consecuencia de las diferencias sobre quién debía financiar ese aumento, cómo lo iba a hacer y qué reflejo tendría todo ello en el nuevo marco regulador. Así, las empresas pretendieron asegurar la independencia de sus ingresos. Garantizado esto, su posición en las negociaciones de carácter estructural fue sólida, de tal forma que pudieron mantenerse en la explotación o lograr un buen acuerdo de rescate. El Estado no podía asumir las cargas del 
rescate tal y como estaban formuladas las leyes de concesión, por lo que, mientras se acercaban los plazos de reversión, trató de controlar a las compañías convirtiéndose en su proveedor de recursos más importante. Las concesionarias detectaron sus intenciones y, lógicamente, se opusieron a ellas, planteando que, o se rescataban las concesiones, o se dejaba libertad para el desempeño de su actividad.

En este artículo se pretende analizar, a partir de las actuaciones del Consejo Superior Ferroviario, los efectos de los cambios de régimen político en el conflicto de intereses que enfrentó al Estado y a las empresas ferroviarias. El trabajo se desarrolla en tres apartados que se corresponden con la cronología que imponen las variaciones de régimen político acontecidas durante el primer tercio del siglo XX en España ${ }^{6}$ : ¿de qué modo afectaron estos cambios a las relaciones e intereses del Estado y de las empresas ferroviarias ${ }^{7}$ Todo ello se inserta de pleno en el ámbito, más amplio, de la regulación y el papel del Estado en la economía, pudiéndose reconocer las diferentes posibilidades teóricas de interpretación de este problema, referidas aquí a una actividad económica esencial, para un país concreto y unas empresas reales, en el largo plazo y en un marco político e institucional incierto ${ }^{8}$. Sin duda, la aproximación institucional para clarificar el conflicto descrito es esencial para una mejor comprensión de la historia del ferrocarril en estos años ${ }^{9}$. La lucha por la recuperación de las competencias entregadas desde 1855 llevó al Estado a dotarse de instituciones que garantizasen el cumplimiento de los contratos y redujesen costes de transacción, en primer término el Consejo Superior Ferroviario y, en 1924, de un nuevo marco regulador - el Estatuto Ferroviario-, con escasa capacidad coercitiva la primera y mucho mayor la segunda ${ }^{10}$. De ahí el interés de estudiar a fondo tanto el Consejo Superior — que será una de las guías del artículo-, como los efectos derivados del Estatuto de 1924.

En todo este tiempo el Estado, con su intervención, ¿pretendió resolver fallos del mercado, recuperar sus intereses en el sector o resolver problemas a las empresas? En este caso, ¿existen diferencias en la acción política de los gobiernos entre los propósitos adoptados y los resultados obtenidos? ${ }^{11}$ Las respuestas —decisiones políti-

6 Las fuentes documentales utilizadas proceden del Archivo Histórico de Renfe (AHR, en adelante), Sección "El problema ferroviario". La documentación de esta sección es escasa para los años 1932-1936.

7 La historiografía española del sector ha avanzado en esta línea de investigación, compaginando en su análisis la actuación de los dos principales protagonistas: Estado y compañías. Véanse Muñoz (1995 y 1999), Comín et al. (1998), Carreras (1999), Ortúñez (1999 y 2004), y Ortúñez y Vidal (2000 y 2004).

$8 \quad$ Millward (2005), pp. 6-7 y 149, propone una pauta de carácter general para buscar patrones comunes de regulación en varios países europeos: el proceso arrancaría en 1913 y las reacciones de los gobiernos, tras los años de la guerra, serían muy similares.

9 Andersson-Skog y Krantz (1999), pp. xvi-xvii; y Greif (2006), pp. 3-23 y 29-53.

10 Greif (2005), pp. 728-730.

11 Magnusson y Ottosson (2001), pp. 1-5; y Gourvish (1999), p. 117. 
cas - influyeron en el comportamiento del sector y en las prácticas de las empresas, pero ¿lograron generar incentivos adecuados? ¿Podría decirse que en la quiebra de las concesionarias tuvieron alguna responsabilidad las organizaciones elegidas por el Estado? Avanzar en el conocimiento de este proceso histórico es especialmente importante en este momento, en el que se asiste al debate originado por un nuevo proceso regulador ${ }^{12}$.

\section{La crisis de la monarquía y su impacto en el sector (1918-1923)}

Los años en que se inició la quiebra del sistema político de la Restauración monárquica coincidieron también con los de la quiebra del sistema de las concesiones ferroviarias vigente desde 1855. Entre 1906 y 1913, las grandes empresas ferroviarias habían conocido los mejores años de la explotación, incluso habían podido repartir más dividendos que nunca a sus accionistas ${ }^{13}$. Sin embargo, la guerra alteró por completo el sistema e incrementó fuertemente los costes de explotación. La profunda crisis financiera que siguió fue el desencadenante de las actuaciones del Estado en la regulación del sector y su intervención en las compañías ${ }^{14}$.

El principal instrumento que el regulador había establecido para controlar el sector, no para asegurar la competencia, era el de reservarse la autorización para que las compañías pudieran incrementar las tarifas. Con el incremento de los costes las compañías necesitaban que el Estado les autorizara tal subida, pero éste se negó sistemáticamente. Tan sólo accedió a un aumento en diciembre de 1918, que no alcanzó las proporciones que las compañías habían solicitado. El problema de la insuficiencia de los ingresos respecto a los costes no se resolvió, pero el Estado se negó a autorizar nuevos aumentos y abrió la puerta al sistema de anticipos —adelantos de fondos por parte del Estado en 1920-, tanto para financiar el coste del aumento de los salarios de los trabajadores, como para que las empresas pudieran modernizar el material de la explotación ${ }^{15}$. Sin embargo, el salto cualitativo que supuso que el Estado

12 Chick (1994), Ramos (2004), Millward (2005), pp. 287-299, y Guillén (2007). Además, se detectan “transferencias" de soluciones reguladoras desde el ferrocarril hacia otros negocios de red y entre diferentes países (Andersson-Skog, 2000).

13 Ortúñez (1999), p. 97; y Pascual (2000), p. 33.

14 Algo similar ocurrió en los ferrocarriles de otros países. Ortúñez (1999), pp. 66-98; Millward (2005), pp. 9198; Caron (1973), pp. 438-441, y (2005), pp. 606-624 y 687-702; Gourvish (1999), pp. 123-124; y Castagnoli (2006). También fueron parejas las soluciones ofrecidas para tratar de superar las dificultades: elevación de tarifas y nuevas regulaciones.

15 Para un análisis más detallado del denominado "problema ferroviario", véase Comín et al. (1998), t. 1, pp. 281-292 y 343-367. 
financiara costes de las empresas ferroviarias tardó todavía unos años en reflejarse en la estructura administrativa de aquél. Hasta 1925 no se creó una Dirección General de Ferrocarriles y Tranvías. Esto indica que los sistemas de control establecidos por el regulador eran prácticamente inexistentes y, en cualquier caso, insuficientes dados el cariz de los acontecimientos y las dimensiones que adquirió el problema ferroviario. Lo cual acarreó que las grandes empresas ferroviarias se relacionaran directamente con los ministros de Fomento y no con organizaciones administrativas estables ${ }^{16}$. Una situación que suponía tanto costes como beneficios para las empresas, pero muchos problemas para el regulador.

La ausencia de transformaciones, en la línea de una nueva regulación o de una estructura administrativa más acorde a la nueva situación, pudo ser consecuencia de los graves condicionantes que afectaban al Estado, entre otros la falta de estabilidad de los gobiernos y las dificultades de la Hacienda española. Entre 1920 y el pronunciamiento del general Primo de Rivera se sucedieron seis gobiernos y ocho ministros de Fomento distintos. Por otra parte, en 1919 la Hacienda estaba "al borde del colapso, con un déficit cercano al 45 por 100 de los ingresos estatales"17.

Cuando las compañías ferroviarias solicitaron del Estado la autorización para incrementar las tarifas, algunos políticos - Cambó, Maura y La Cierva, entre otroscomprendieron que había llegado el momento de replantearse la situación jurídica en que se encontraban las compañías ferroviarias, aunque se verían condicionados por la inestabilidad de los gobiernos, el reducido tamaño del Estado y de los presupuestos, las deficiencias del sistema fiscal, el problema obrero y su mentalidad liberal respetuosa con el capital privado, que impedía soluciones radicales. Todo ello unido hacía imposible, en la práctica, otra solución diferente de la de adelantar fondos a las empresas; pero eso sí, a partir de ese momento habría que dejar claro en los balances de las compañías qué activos les pertenecían a ellas y cuáles al Estado. Así, los dos anticipos autorizados en 1920 y prorrogados después eran, en realidad, préstamos: el primero, para incrementar los salarios a los trabajadores, sin intereses; y, el segundo, para adquirir material móvil y de tracción, con un interés anual del 5 por $100 \mathrm{y}$ a devolver en veinte años.

Sin embargo, la capacidad de controlar a los concesionarios apenas experimentó cambio alguno. La única medida que el Estado sancionó antes del pronunciamiento militar fue la creación del Consejo Superior Ferroviario, aprobado por Real Decreto en marzo de 1922 por el gobierno conservador de Sánchez Guerra, poco partidario de la intervención directa del Estado, pero consciente de las dificultades del sector, que trató de resolver contando con las grandes empresas. Este Consejo era el 
único vestigio que quedaba del proyecto de ordenación ferroviaria elaborado por el anterior gabinete de Maura, concretamente por Flores de Lemus a instancias del propio Maura ${ }^{18}$. Con Argüelles en la cartera de Fomento, el Consejo Superior Ferroviario conservaba como finalidad la de "estudiar y proponer al gobierno las resoluciones que deban adoptarse en relación con los ferrocarriles de servicio general y uso público"19 y dependía directamente del ministro de Fomento. Surgió con la finalidad de ser órgano consultivo y de inspección del gobierno en materia de ferrocarriles y empresas ferroviarias. Es, por tanto, reflejo directo de la asunción por parte del Estado del papel que estaba llamado a desempeñar en la solución del problema y de la responsabilidad que le correspondía, primero, por participar parcialmente en la financiación de la actividad y, segundo, por la importancia del sector para el conjunto de la economía. En esta medida pueden vislumbrarse las ideas del Estado y los condicionantes con que éste tropezaba. El gobierno pretendía desligar del Ministerio algunas funciones en materia ferroviaria, apostando por la vía de resolver primero lo coyuntural.

El Consejo estaba compuesto por el ministro de Fomento como presidente y quince vocales: seis ostentaban la representación del Estado — cuatro eran propuestos por el ministro de Fomento y dos por el de Hacienda-, otros seis constituían la delegación conjunta de los concesionarios de ferrocarriles en explotación, y tres más representaban a los intereses mercantiles, industriales y agrícolas. Además del presidente, los quince miembros debían elegir un vicepresidente por mayoría absoluta que no podía proceder de la delegación de los ferroviarios ${ }^{20}$. Se trataba del típico organismo público de la época, más o menos autónomo, de carácter marcadamente

18 Ortúñez (1999), p. 135.

19 Artículo primero del Real Decreto. El Consejo quedó constituido el 6 de abril de 1922. Desde entonces y hasta el 20 de noviembre de ese año, se reunió en diez ocasiones. Después no volvió a hacerlo hasta el 2 de octubre de 1923. Esta "segunda fase" del Consejo Superior Ferroviario terminará en diciembre de 1923, habiéndose reunido doce veces. El Directorio Militar creó el 30 de enero de 1924 el Consejo Superior de Ferrocarriles, continuador del anterior. La documentación de este último se encuentra muy dispersa, pero es muy abundante, pues con la Dictadura el Consejo adquirió un papel decisivo.

20 Miembros del primer Consejo fueron, además del ministro Argüelles, Alfredo Mendizábal, Leonardo Torres Quevedo, Francisco de la Torre, José María Madariaga, Enrique de Illana y Juan Díaz de la Sala, por parte del Estado; Basilio Paraíso (en julio de 1922 presentó la dimisión; por entonces se encontraba en lucha contra las medidas fiscales que trataba de adoptar el gobierno), el vizconde de Eza y Domingo Sert (presidente del Fomento del Trabajo Nacional, más tarde será uno de los apoyos de Primo de Rivera en Barcelona), en la representación de los intereses económicos; y Eduardo Maristany, Félix Boix, Rafael Coderch, Cirilo Aleixandre, Manuel Alonso y el vizconde de Escoriaza en la representación ferroviaria. Con el cambio de régimen los representantes del Estado dimitieron. A Paraíso le sustituyó Carlos Prats, presidente de la Cámara de Comercio de Madrid, quien formará parte de la Asamblea Nacional Consultiva en representación de los "intereses". El vizconde de Eza dimitió en julio de 1922 y le sustituyó el conde de Montornés. AHR, "El problema ferroviario"; y Cabrera y del Rey (2002), pp. 185, 195 y 210. 
corporativo, absolutamente inútil como se verá, en el que cada delegación entendía de modos diferentes, y a menudo irreconciliables, el concepto tan manido de "economía nacional". Entre otras funciones, correspondía al Consejo en pleno "proponer al gobierno los planes de obras de ampliación o mejora y las adquisiciones de material" que tuvieran que hacer los concesionarios. El Estado, asimismo, le transfirió sus competencias en materia de tarifas. En la sesión constitutiva el ministro hizo notar:

"la importancia y trascendencia de la labor que el Consejo ha de realizar, no sólo en cuanto afecta al estudio y soluciones que, de momento, demanda el magno problema de los transportes ferroviarios, acaso el más interesante de cuantos al presente se hallan planteados para la economía general del país, sino también porque ha de constituir un organismo capacitado para que, llegado el día de la reversión o rescate de líneas o redes ferroviarias, se verifique con las máximas garantías de que no se perturbará la normal continuación del servicio"21.

Confiaba en que el proyecto de ordenación ferroviaria, después fallido y que iniciaba su andadura parlamentaria, arribase a buen puerto y alumbrase una nueva era de la explotación. Para llegar a ello, dos asuntos fundamentales marcaban la agenda del Consejo. Primero, dotarse de unos estatutos de funcionamiento; segundo, establecer algún tipo de acuerdo que permitiera la elevación de las tarifas ferroviarias, "ya que la situación del Tesoro impone la necesidad de llevar a ella, a fin de liberar al Estado del agobio que para su Hacienda representan las indemnizaciones que hoy abona"22. El acuerdo sobre los artículos del Estatuto se alcanzó sin demasiadas dificultades, pero nunca se logró respecto a las tarifas — se presentaron dos opciones en las que hubo completa división entre representantes del Estado y de las compañías, situación que el primero no llegó a resolver ${ }^{23}$ - . Del análisis de las actas se deduce que, a pesar de la corrección en las formas y de las ganas de trabajar y de aclarar el presente y futuro de las concesiones ferroviarias, la labor del Consejo resultó estéril, no se llegaron a acuerdos en las cuestiones fundamentales y siempre hubo discrepancias, votos particulares o adiciones a escritos con otras opiniones. En diciembre se producía el último cambio de gobierno de los liberales y del sistema de la Restauración, con lo que se interrumpió la labor del Consejo Superior. El último gabinete, acuciado por los problemas políticos, no dispuso de margen suficiente para ocuparse del sector ferroviario.

\footnotetext{
21 Acta primera del Consejo Superior Ferroviario, 6/04/1922, p. 1. Nótese la calculada imprecisión: reversión o rescate, de líneas o redes. Son cuatro conceptos diferentes.

Acta primera del Consejo Superior Ferroviario, p. 2.

Para el Estado y los representantes de los intereses económicos bastaría con un aumento del 13,5 por 100, pero los de los concesionarios vieron necesario llegar hasta el 15 por 100.
} 
En estos años el Estado, que descartó incrementar las tarifas, avanzó, empero, hacia una mayor intervención en el sector: sus aportaciones constituían un patrimonio diferenciado del de las compañías, lo que le llevó a buscar — con el Consejo Superior- nuevos órganos de control. El problema fundamental al que se enfrentó, y que favoreció la defensa de las empresas, fue la inestabilidad de los gobiernos constituidos, así como la existencia de graves problemas políticos en el régimen de la Restauración y dentro de los principales partidos. El Estado no tuvo una estrategia clara de actuación con el sector ferroviario. La división política, la fragmentación y las reducidas mayorías parlamentarias dificultaron aún más cualquier solución de calado destinada a perdurar. Por otro lado, no solo recibió de las empresas concesionarias numerosas presiones procedentes de diversos frentes, sino que las que soportó para no aumentar las tarifas - aunque estén todavía poco estudiadas- fueron considerables. Además, las campañas contra las compañías, que no omitían ni el insulto ni la difamación, fueron muy virulentas ${ }^{24}$. De esta suerte se vio obligado a decidir encerrado entre dos fuegos, aunque sí puede apreciarse que se sacudió la supuesta captura de años anteriores, pues había otros intereses que contraponer y las compañías estaban atrapadas entre el rescate y las tarifas.

Por parte de las compañías, la crisis de resultados que generaron las pérdidas sufridas durante la Gran Guerra, les llevó a solicitar la autorización para incrementar las tarifas. Consiguieron en 1918 un aumento, de cuantía menor a la que habían demandado, cuya suma debían contabilizar por separado del resto de los ingresos, para que, cuando se alcanzara el rescate de las concesiones, el Estado no pagase dos veces $^{25}$. Lo concedido por el Estado no se adecuaba, por tanto, a su estrategia en la defensa de los intereses del capital social, pero no les quedó más remedio que aceptarlo, adaptarse a las diversas medidas estatales y esperar, ilusoriamente, a que llegaran tiempos mejores.

\section{Las compañías ferroviarias ante la dictadura (1923-1931)}

El Directorio militar hizo del desprecio por los partidos políticos del régimen anterior y por sus principales representantes uno de los motivos que justificaban el pronunciamiento: la ineficacia de los políticos y del sistema parlamentario explicaban los problemas que tenía el país. Estos hechos convirtieron el problema ferroviario en un objetivo clave para la propaganda del nuevo régimen: la Dictadura sería capaz de

\footnotetext{
24 Ortúñez (1999), p. 119.

25 Muñoz (1999), pp. 305-306.
} 
resolver lo que el régimen parlamentario no había conseguido ${ }^{26}$. El nuevo gobierno abordó enseguida el problema y, tras unos meses de estudios muy detallados que ofrecen abundante información acerca de las empresas, promulgó el decreto de 12 de julio de 1924, que daba origen al llamado Estatuto ferroviario ${ }^{27}$. No es posible en estas páginas estudiar en profundidad su contenido, pero supuso, de hecho, una nueva regulación del sector, aunque no se lograse llevar íntegramente a la práctica. $\mathrm{Al}$ comienzo de su aplicación, las empresas llegaron a cuestionarse la vigencia de sus estatutos al entender que sus fines constitutivos habían sido modificados con el nuevo régimen, que les privaba de competencias fundamentales en materias financieras y de toma de decisiones estratégicas.

El proyecto de nuevo régimen ferroviario fue estudiado por el Consejo Superior de Ferrocarriles, continuador del Consejo Superior Ferroviario ${ }^{28}$. Se creó por Real Decreto de 30 de enero de 1924 con el objeto fundamental de informar sobre el proyecto de nuevo régimen ferroviario, de 14 de enero de 1924, que había elaborado la Ponencia nombrada por el Directorio militar. Apenas se sabe nada sobre dicha Ponencia, ni el momento concreto de su creación, ni sus miembros, ni siquiera de quién dependía dicho organismo; pero todo invita a pensar que era la voz del gobierno sobre el asunto. De hecho, le fue llegando toda la información que éste había solicitado y fue quien presentó, el 28 de diciembre de 1923, el texto del proyecto del nuevo régimen ferroviario. Es posible que el autor más destacado de dicho proyecto fuera el teniente coronel Gil Clemente, conocido por su enconada oposición a las empresas privadas ${ }^{29}$, pues desde, cuando menos, el 29 de septiembre había recibido

26 En el acta del Consejo Superior Ferroviario de 15/10/1923 quedó constancia de las palabras dirigidas a los nuevos miembros del mismo por el jefe del gobierno: que tuvieran la "mayor urgencia en despachar los asuntos de trámite y cuantos se sometan a su deliberación, para que sirvan de ilustración al resolver cuanto se relacione con el régimen ferroviario, que es urgentísimo terminar de una vez". En esa misma reunión, Prats manifestó "el contraste entre el referido encarecimiento de la mayor rapidez en el despacho de los asuntos encomendados al Consejo y la que en situaciones anteriores existía que obedecía al imperativo de no hacer nada".

27 Se resumen así todas las iniciativas adoptadas en octubre de 1923 entre las que destacan la información pública que convocó el Directorio para recabar propuestas sobre régimen ferroviario (se recopilaron cerca de 300 ponencias), un llamamiento en este mismo sentido a los vocales del Consejo Superior o la creación de comisiones investigadoras de la contabilidad de las empresas. Después llegó la presentación del proyecto de nuevo régimen ferroviario, la creación del nuevo Consejo y el estudio de dicho proyecto, hasta la aprobación del Estatuto ferroviario en 12 de julio de 1924.

28 No se trató sólo de un cambio de nombre, sino que existieron cambios cualitativos de importancia que supusieron un mayor control de las empresas. Se trata, en consecuencia, de un cambio relevante en una organización acaecido con el cambio institucional.

29 En la exposición previa (que luego permaneció en el Decreto) se explicaba que, con el cambio de régimen, no se trataba de convertir en buenos los malos negocios ferroviarios, sino sólo mejorar los servicios; "si con las mejoras, con buenos servicios de explotación, con medidas indirectas de gobierno y con tarifas adecuadas el negocio no prospera, será porque el ferrocarril no responda a una verdadera necesidad comercial, 
informes diversos sobre el régimen de anticipos y el problema ferroviario ${ }^{30}$. El proyecto fue presentado por el general Mayandía, uno de los vocales que componían el Directorio militar, quien ofreció un plazo de cinco días hábiles a las empresas para que efectuasen las observaciones que considerasen oportunas. Tras las réplicas y contrarréplicas, el proyecto se publicó el 14 de enero de $1924^{31}$.

Cuando el 30 de enero nació el Consejo Superior de Ferrocarriles, a las funciones que tenía el anterior se añadió la de informar sobre este proyecto y la de implantar la organización del régimen ferroviario que se adoptase. Se amplió el número de vocales, pasando de quince a diecisiete, al asignarse uno a los usuarios (representados por las corporaciones mercantil, agrícola, minera e industrial) e incorporarse un representante de los trabajadores ${ }^{32}$. En el mismo Real Decreto se mantenía el aumento de tarifas aprobado en 1918, pero se procedía al desmantelamiento progresivo del anticipo aprobado en 1920 y destinado a la mejora salarial de los trabajadores ferroviarios, sin que esto significara una reducción de sus percepciones, sino que en adelante lo asumirían las empresas sin ayuda estatal. Esta medida suscitó una respuesta unánime de todas las empresas ferroviarias españolas, nada conformes con ella.

porque el agio ha predominado en relación con la explotación, porque se ha querido obtener una subvención y no organizar un transporte". En la base primera se decía: "La intervención directa del Estado en las explotaciones ferroviarias está impuesta por los intereses públicos. El Estado intervendrá los ferrocarriles dentro del Nuevo Régimen Ferroviario con auxilios directos a las Empresas y regulando la gestión ferroviaria autónoma de los concesionarios". Junta Superior de Ferrocarriles (1940), t. 1, pp. 155 y 157. AHR, "El problema ferroviario", de 29 de septiembre a 16 de octubre de 1923.

31 Junta Superior de Ferrocarriles (1940), t. 1, pp. 123-147. Para el Directorio lo esencial era el servicio de transporte por su incidencia en la economía y defensa, mientras que para las compañías lo eran los intereses empresariales. Pero, como dijo Gil Clemente en su contestación a las observaciones que hicieron estas últimas, "lo que conviene al país es robustecer las instalaciones, los ferrocarriles, no las empresas; lo que conviene es mejorar las instalaciones, aumentar el material fijo y móvil en general"; declaración que permite comprender mejor el porqué de la Caja Ferroviaria y cuál era la posición del gobierno.

32 El primer Consejo, publicado en la Gaceta de Madrid de 22/04/1924, quedó constituido por los siguientes vocales: en representación del Estado, Alberto Machimbarrena, Carlos Santa María, Antonio Fernández, Julián Gil Clemente, José Artigas y el coronel jefe del servicio de ferrocarriles, Fermín Sojo, se designaba además a los suplentes; por los concesionarios, Félix Boix, Eduardo Maristany, Rafael Coderch, Cirilo Aleixandre, Manuel Alonso y el vizconde de Escoriaza. El Instituto de Reformas Sociales designó al vocal representante de los agentes y obreros ferroviarios, Francisco Carmona, su suplente fue Aníbal Sánchez Ferrer. La representación de los usuarios quedó constituida por Mariano Matesanz (muy contrario a los intereses de las empresas), Carlos Prast, Domingo Sert y Aniceto Sela. En el puesto de secretario, Sánchez Torres. Sobre esta composición comentó Maristany que se habían buscado enemigos de las compañías y partidarios del estatismo al estilo Gil Clemente. Entre sus funciones, ampliadas con el Estatuto y en 1925, destacaban la de intervenir en la ordenación de las obras y trabajos que tendiesen a la estructuración racional de la red, así como en las obras de ampliación y mejora de la misma, en la adquisición de material y construcción de líneas nuevas y en cualquier tipo de obra ferroviaria. Se subdividió en cuatro secciones: explotación comercial, unificación de material, contabilidad y caja ferroviaria, y agrupación de líneas. 
La tensión entre Estado y concesionarios en los meses transcurridos desde el pronunciamiento y la aprobación del Estatuto ferroviario fue máxima. El primero apretó mucho, sus intervenciones y expresiones impresas se contaban por ofensas e, inevitablemente, las empresas vieron en el nuevo Consejo y en su composición un procedimiento para aislarlas ante la opinión pública y garantizar así el éxito de la solución que desde el gobierno, a través de la Ponencia del Directorio en materia ferroviaria, se había adoptado, sin tener en cuenta ninguna de sus opiniones expresadas por extenso durante todo este tiempo.

Por otra parte, y a más corto plazo, a las concesionarias les inquietaba que la tramitación que el proceso legislativo debía seguir retrasaría la adopción de medidas definitivas, mientras que desde febrero empezaría la reducción de los anticipos; es decir, las empresas se verían privadas de una fuente importante de recursos sin poder adoptar ninguna medida que contrarrestase esos efectos negativos. Ésta era una de las cuestiones que más les preocupaba, pues desconfiaban de que los problemas financieros se pudieran resolver antes de ocasionar su quiebra. De hecho, cuando se aprobó el Estatuto en julio, las compañías, que no habían entrado a fondo en la batalla de las ideas contra el gobierno (el tipo de régimen de explotación que se instauraría: consorcio-comunidad o concesiones), se verán abocadas a ingresar sin rechistar en el nuevo régimen para tratar de mantener y mejorar sus resultados económicos. Si el gobierno empleó la supresión de los anticipos y la creación del nuevo Consejo Superior y su composición como una estrategia de distracción, habría que felicitarle por su extraordinaria habilidad. De todos modos, es difícil pensar que fuera así, pero esto permitió valorar la delicadísima situación financiera en que se hallaban las empresas ferroviarias, incluidas las grandes, y poderlas manejar a su antojo cuando se les pusiera en la tesitura de que sólo existirían recursos dentro del Estatuto. Fuera de él las compañías deberían regresar, a todos los efectos, a la legislación originaria de cada concesión, con la supresión de la elevación de tarifas de 1918, la imposibilidad de emitir deuda y, en definitiva, sin financiación: el Estatuto fue adoptado mayoritariamente $y$, desde luego, por las grandes; y ello a pesar de que suponía que el sistema de concesiones surgido con la ley general de 1855 quedaba de facto abolido.

Las discusiones previas a la aprobación del Estatuto en el seno del Consejo Superior de Ferrocarriles precisaron de 43 sesiones, celebradas entre febrero y mayo de $1924^{33}$. El 31 de este último mes emitió un dictamen sobre el proyecto presentado por la Ponencia, plagado de votos particulares. El nuevo régimen suprimía los derechos de las empresas otorgados por el sistema de concesión, que constituían verda-

33 No se han localizado las actas de esas sesiones, sí copias sueltas de algunas de ellas. 
deros contratos bilaterales. Su rescisión estaba prevista en la legislación de 1855, pero sus modificaciones debían ser pactadas. En opinión de las compañías, el Estatuto no se inclinaba decididamente por la "estatificación" de las explotaciones, pero tampoco las mantenía en la esfera de una iniciativa privada oportunamente restringida por una intervención estatal racional, sino que la opción era el consorcio, la asociación de Estado y concesionarias. Una asociación difícil por la asimetría existente entre las dos partes, que no contaban con intereses siempre comunes y en la que uno de ellos concentraba una fuerte capacidad coactiva. También arremetían contra el Consejo Superior, el instrumento diseñado por el Estado para dirigir toda esta política, cuyas funciones eran vistas como injerencias capaces de desorganizar el normal funcionamiento de las empresas. Lamentaban además la multiplicación de trabajo que les supondría atender a sus requerimientos y a los gastos de sostener toda esa burocracia $^{34}$. El tiempo se encargaría de darles la razón en otra cuestión, la financiera. La asunción por parte del Estado de la misión de aportar los capitales necesarios constituyó motivo de preocupación, pues, como escribieron al gobierno, la deuda pública era enorme y el desequilibrio entre los ingresos y los gastos del erario un mal endémico. ¿Había margen para asumir esa ingente tarea? ¿Por cuánto tiempo?

Las diferencias entre el proyecto presentado por la Ponencia del Directorio y las bases aprobadas en el informe del Consejo Superior fueron de importancia en algunos casos. Entre este texto y el del Estatuto Ferroviario casi no existieron; se trató mayoritariamente de cuestiones de redacción y de la reducción de plazos en las diversas materias en que éstos se fijaron. Algunas de esas modificaciones favorecieron los intereses de las compañías, en especial al proteger una mayor autonomía en la gestión de la que se contempló en el primer texto ${ }^{35}$. Pronto el pesimismo se apoderó de los órganos directivos, que vieron en la incorporación al nuevo régimen tan sólo un mal menor ${ }^{36}$. Se trataba de un sentimiento agridulce que las empresas resolvieron por razones prácticas. Como dijo Maristany, no se podía aconsejar quedarse fuera del nuevo régimen y, en consecuencia,

"aún viendo los serios peligros que tiene el ingreso en el mismo, debe acordarse éste porque serían más inmediatos, más seguros y más graves los que se producirían de rehusar dicho ingreso" ${ }^{\prime 37}$.

AHR, "El problema ferroviario", 27/05/1924.

AHR, "El problema ferroviario", nota sobre las modificaciones introducidas por el Consejo Superior Ferroviario, junio 1924. Es difícil valorar la reacción de las empresas a las diferencias que introdujo el Directorio en el texto del Consejo, por resultar esta contradictoria: en ocasiones se habla de mejora, pero en otras de que las modificaciones lo habían empeorado mucho. 
Y ¿cuáles eran esos "peligros" para las compañías que permiten ahondar en el conflicto de intereses existente? Algunos ya han sido señalados, pero es posible apuntar los que Maristany pensaba indicar al Consejo de Administración de MZA: se retiraba a la compañía la capacidad de emitir obligaciones con vencimientos mayores que los de la concesión; se le quitaban 75 millones de pesetas de capital real (lo que incidía directamente en la valoración de la empresa en caso de rescate); perdía la facultad exclusiva de la percepción de la tarifa y la libre disposición de sus fondos sobrantes, así como la perpetuidad de las líneas libres (es decir, las que no tenían plazo definido de reversión y, por tanto, lo eran teóricamente a perpetuidad); se le imponían límites en la organización y realización de sus actividades; quedaba mediatizada técnica, económica y financieramente por el Consejo Superior; y venía a constituir con el Estado un consorcio o comunidad de bienes y dejaba de ser verdadera concesionaria. Pero junto a estos problemas, Maristany expuso también las razones para entrar, particularmente reveladoras y, en verdad, irresistibles:

"no podemos vivir sin el 15 por 100 ni los anticipos; el R. D. está basado en que el ferrocarril se baste a sí mismo y para conseguirlo un día u otro tendremos la salvación por este lado; no hay que esperar que, aun cuando desaparezca el Directorio, cambie el R. D., ya que éste en su esencia no es más que variación de los proyectos de Maura y Argüelles; es por lo tanto difícil que nadie lo eche abajo (...); si no entramos los empleados nos obligarán a entrar; no olvidemos que tenemos 34 concesiones distintas y que el gobierno tiene en su mano con arreglo a las leyes actuales el rescate de las mejores, que puede obligarnos a llevar contabilidad de ingresos y gastos por cada concesión haciéndonos la vida imposible; que es un sueño pensar que podríamos vivir aplicando las tarifas máximas legales; que tenemos una serie de problemas [de infraestructuras] en Madrid y Barcelona y además las dobles vías que no podríamos resolver por nuestras propias fuerzas"38.

Esta larga reflexión es fundamental y pone de manifiesto, por un lado, la contradicción en la que se debatieron las empresas y, por otro, que el Estado impuso unas reglas del juego con las que, de hecho, obligaba a las compañías a entrar en el nuevo régimen. Ello no fue, sobra decirlo, fruto de una casualidad o del azar, sino una decisión adoptada con información solvente, tras varios meses de estudio y reuniones, y con la que se perseguía mejorar el sistema ferroviario, atando más en corto a sus concesionarios. En definitiva, se volvía a regular el sector, 69 años después de

38 AHR, "El problema ferroviario", 21/07/1924. Aunque no se disponga de documentación tan detallada para la compañía Norte, lo que se sabe a través de los órganos en que confluían ambas en el propio Consejo Superior, o por la correspondencia que cruzaban sus directores generales, Maristany y Boix, refleja un mismo sentir y unánime parecer. 
la primera ley general, y se hacía removiendo obstáculos a las grandes empresas y casi olvidando a las pequeñas, que recibieron muy pocos fondos de la Caja Ferroviaria. La explotación no cambiaba de manos, aunque se amenazaba con hacerlo y se articulaban procedimientos en esa línea, pero el Estado recuperaba mucha capacidad, control e iniciativa, al tiempo que se engarzaba en la costosa tarea de modernizar la red y el material de explotación, tarea para la que ni las grandes contaban con medios suficientes. El Estado se comprometía con el servicio ferroviario y no desdeñó incautarse, en 1928, de la Compañía de Madrid, Cáceres y Portugal y Oeste de España, para mantener y garantizar la explotación de esas líneas.

A través del Estatuto, el gobierno trató de reducir el valor de las empresas e incrementar la participación estatal en el activo ante el posible rescate de las concesiones. Con la Caja Ferroviaria, que comenzó a funcionar a finales de 1925, financió el desarrollo y mejora de las infraestructuras ferroviarias y la modernización del material de explotación, además de introducirse en la construcción de algunas pequeñas líneas, lo que redujo las inversiones de las propias empresas. La bonanza con la que se comportaron las principales magnitudes económicas españolas en estos años, permitió a las dos grandes mejorar los resultados de la explotación ${ }^{39}$. Éstas aprovecharon la ocasión para repartir más dividendos a los accionistas. Las inversiones realizadas por el Estado le permitían sentirse como un socio más de la explotación y considerar que había quedado extinguido el régimen de concesiones nacido en $1855^{40}$. La financiación estatal de gran parte de los costes de las empresas ponía en evidencia que las compañías no podían pretender seguir operando como propietarios de las redes y del material que empleaban, pero hizo muy complejo establecer los derechos de cada parte y, años más tarde, cuando se procedió a su nacionalización, valorar las indemnizaciones debidas. El Estatuto prohibió a las empresas, además, que aumentaran el endeudamiento mediante la emisión de títulos de renta fija.

La principal fuente de financiación de la Caja Ferroviaria procedió de la emisión de la deuda especial ferroviaria del Estado, aunque se contemplaba también que pudiera beneficiarse de una asignación anual realizada desde los presupuestos ordinarios. El Estado sólo pudo mantener este sistema de financiación hasta septiembre de $1930^{41}$. Para entonces también habían caído Primo de Rivera y su principal valedor en las obras públicas, el ministro Benjumea, aunque no la Dictadura. Con la desaparición de la Caja y arruinado el crédito de las compañías en el mercado de

39 Carreras y Tafunell (2005), capítulos 5 y 17; y para las empresas ferroviarias, Ortúñez (1999), pp. 577-579.

$40 \quad$ Ortúñez (1999), p. 207.

41 El 68 por 100 de los ingresos de la Caja procedieron de la negociación de la deuda y el 3,6 por 100 de los presupuestos ordinarios. El resto tuvo orígenes variados: reintegros de los anticipos realizados por el Estado desde 1920, deudores y préstamos, y anticipos suscritos con garantía de deuda ferroviaria. Ortúñez (1999), p. 265. 
capitales, la financiación de éstas se convirtió, tal y como habían advertido las empresas, en un problema de difícil solución. En consecuencia, es posible considerar que las empresas ferroviarias no capturaron al Estado en los años de la Dictadura. Lo que ocurrió, desgraciado también para ellas, lo habían vaticinado los gestores ferroviarios y a eso precisamente se habían enfrentado. Ante lo inevitable de su ingreso en el régimen del Estatuto, se adaptaron al resquicio positivo que les facilitó una buena coyuntura y una sustancial reducción de determinados costes que financiaba el Estado y que además les permitía ofrecer un mejor servicio: repartir dividendos a sus accionistas.

El Estatuto Ferroviario, además, potenció el Consejo Superior de Ferrocarriles. Sus competencias pueden resumirse diciendo que era la organización del Estado que monopolizaba las actuaciones en materia ferroviaria: controlaba las empresas, la Caja Ferroviaria y la deuda; decidía sobre las obras a realizar; estudiaba y desarrollaba el Estatuto, las tarifas y la posible reversión al Estado de las concesiones; revisaba la legislación existente en materia ferroviaria, etc. El gobierno había garantizado su control, aunque con un margen muy estrecho. En el transcurso de estos años recibió nuevas atribuciones, reorganizándose en octubre de 1925 en nueve secciones $^{42}$. Un nuevo Real Decreto de 17 de diciembre de 1925 creó el Comité Ejecutivo del Consejo Superior. Ello podría interpretarse como una nueva evidencia de que las compañías tenían razón cuando advirtieron del exceso de burocracia que iba a generar el Consejo, el cual podría retrasar y dificultar el trabajo de gestión. A las empresas les preocupaban, en este sentido, los efectos paralizadores que se derivarían de una estructura de gestión compleja, con muchos intereses contrapuestos y de equilibrios inestables; pero el gobierno percibió que le resultaba difícil en ocasiones doblegar, ya no sólo los intereses de los concesionarios, sino también, en algunos casos, los de los representantes de los intereses económicos. Estas tensiones se pretendieron resolver mediante un Comité Ejecutivo y otorgando una función meramente consultiva al pleno del Consejo, cuando las normas legales anteriores habían ampliado sus funciones, tareas y responsabilidades. La reforma se planteó en aras de la eficacia.

Además de este órgano, el organigrama del Ministerio de Fomento se modificó de forma sustancial con la creación, el 25 de diciembre de 1925, de una nueva Dirección General con competencias exclusivamente para Ferrocarriles y Tranvías. Rafael Benjumea había sido nombrado el 3 de diciembre ministro de Fomento. Pocos días después, por tanto, se creaba este instrumento que, como se decía en la exposición de motivos del Real Decreto, había "surgido como una exigencia de la realidad". Tras

42 Éstas fueron: Asuntos generales y legislación, Contabilidad y Caja, Explotación comercial, Explotación técnica, Unificación de material, Construcción de ferrocarriles, Agrupación de líneas y rescates, Fijación de capitales y Ferrocarriles del Estado. 
el impulso que el Directorio había imprimido a todas las obras públicas, se requería el organismo administrativo adecuado que acompañara toda esta labor ferroviaria de manera exclusiva. Esta nueva disposición puede leerse, también, bajo la misma clave de interpretación que la de la creación del Comité Ejecutivo; con el establecimiento de esta Dirección General, el gobierno reforzaba sus competencias en materia ferroviaria $y$, en consecuencia, su derecho a controlar más de cerca sector y empresas. Como en realidad el Estado ya se sentía legitimado para intervenir y controlar, su función incluía, además, los más "extensos desenvolvimientos, no sólo en el orden económico-financiero y jurídico, sino en el puramente constructivo, en el facultativo en todos sus aspectos, en el administrativo con todas sus derivaciones; lógicos corolarios de los nuevos principios en los que se ha inspirado la reforma" 43 .

Con el ingreso en el régimen del Estatuto, los órganos de dirección de las grandes empresas ferroviarias no pensaron en otra cosa que en el modo de defender su capital social para cuando se produjera el rescate ante lo que consideraban acometidas estatales en esa dirección. Esta reacción de los empresarios permite pensar que el nuevo marco regulador, someramente descrito, adoleció de algunos defectos en su formulación, pues trazó a los gestores un camino a seguir equivocado. Quizá fue el principal el de no haber sabido transmitir calma y seguridad a las empresas, ni haber generado la estructura de incentivos suficientes para que éstas se hubieran volcado en una adecuada gestión de sus negocios, con unos medios que mejoraron de modo evidente ${ }^{44}$. El error, asimismo, de haber cercenado las fuentes de financiación de las empresas - al no autorizar libertad y flexibilidad en el régimen de las tarifas, ni nuevas emisiones de obligaciones - y de haber considerado que el recurso a la deuda pública sería manantial inagotable, contribuye a explicar dicha reacción. Los resultados obtenidos hasta la quiebra del régimen del Estatuto y de la Caja Ferroviaria muestran que la opción era acertada, pero que había que lograr hacerla perdurar en el tiempo sin que cargara sobre el Estado. Éste intervino para resolver fallos en el mercado, no para solventar situaciones particulares a las empresas. Sin embargo, logró un efecto contrario, puesto que no dio continuidad en las ayudas al sector y, aunque sólo coyunturalmente, esas medidas favorecieron a las grandes empresas. Por lo cual es posible añadir que existieron diferencias entre los propósitos adoptados

43 Real Decreto de 17 de diciembre de 1925. En su exposición de motivos se insistía en el carácter meramente consultivo del Consejo Superior, lo que prueba que se quería recuperar el poder entregado a éste.

44 Ortúñez (1999), pp. 247-267 y 295-307. Las empresas interpretaron toda la intervención con las mismas claves que desde 1918, es decir, rescate disimulado que llegaría antes o después; y si la Dictadura perduraba, más antes que después. Y el Estado, que evidentemente pensaba en el rescate desde hacía ya años, pretendía, como punto de partida, poner el sector en condiciones óptimas de explotación, pero ya se vería cómo y cuándo se hacía el rescate. Para ello se contemplaba un proceso gradual de implantación del Estatuto: transitorio, provisional y definitivo. 
y los resultados obtenidos, y lo fueron como consecuencia de una regulación deficiente que, además, no se logró culminar en todas sus disposiciones y fases preestablecidas.

El nuevo régimen insistió a las empresas en la línea de la nacionalidad del Consejo de Administración y del director y los jefes de servicio, imponiendo que, además de los dos tercios de los miembros del Consejo de Administración, su presidente fuera español y que las nuevas empresas ferroviarias que se constituyeran no pudieran tener ningún órgano de dirección compuesto mayoritariamente por extranjeros o fuera del territorio nacional. Norte y MZA tenían una rama del Consejo de Administración en París. Además, el Estado había aprobado en octubre de 1923 el decreto de incompatibilidades para ex-ministros, con el que se les obligaba a abandonar sus puestos en los Consejos de Administración. Este decreto, vigente hasta 1928, afectó a las empresas ferroviarias e intensificó el proceso de sustitución de políticos por representantes del sector financiero y de los grupos industriales, como muestra el Cuadro 1 para el caso de MZA. De ahí que en los Consejos de Administración de las empresas ferroviarias, durante estos años, estuvieran sentados los bancos más importantes del país ${ }^{45}$.

Las transformaciones derivadas de la aplicación del Estatuto condujeron a un sistema de gestión cada vez más gerenciall ${ }^{46}$, con el fin de garantizar o proteger los intereses de los propietarios, puesto que la práctica hacía que la información y la toma de decisiones recayera en la persona del director general, persona de la máxima confianza de los accionistas mayoritarios ${ }^{47}$. El papel de los Consejos de Administración se reducía al de sancionar lo que presentaba el director general. La relación que existe entre la aprobación del nuevo régimen y el hecho de que se reforzara el sistema gerencial radica en las más intensas, por frecuentes y decisivas, relaciones que mantuvieron las empresas con el Estado. Este hecho fue la consecuencia, primero, de las negociaciones que tuvieron lugar para la modificación legislativa y, después, de su progresiva aplicación y, de modo particular, de aquellos puntos en los que se dirimía acerca del valor de las empresas. Los continuos requerimientos del Estado y los esfuerzos encaminados a la defensa de sus intereses dificultaban que la toma de decisiones de las empresas se realizara en reuniones del pleno del Consejo de Administración, en donde todos los consejeros pudieran disponer de la información necesaria. Fueron los directores generales de Norte y MZA y sus hombres de confianza los representantes de las compañías en el Consejo Superior de Ferrocarriles y en las comisiones que de éste se derivaron.

\footnotetext{
45 Para Norte y MZA, Comín et al. (1998), t. 1, pp. 317-328; y Vidal y Ortúñez (2002). Para Norte, Vidal (1999), pp. 627-641. Para MZA, Ortúñez (1998).

$46 \quad$ Vidal (1996), p. 288.

$47 \quad$ Ortúñez (1998), p. 38.
} 
CUADRO 1

REPRESENTANTES DE GRUPOS FINANCIEROS

EN EL CONSEJO DE ADMINISTRACIÓN DE MZA*, 1914-1924

\begin{tabular}{cl}
\hline Fecha & \multicolumn{1}{c}{ Grupos financieros } \\
\hline antes de 1914 & Casa Rothschild, Banco Urquijo \\
1915 & Banca Sáinz, Banco de Barcelona, Casa Bauer \\
1918 & Banca Aldama \\
1919 & Banco Hispano Americano \\
1920 & Banco de Vizcaya \\
1924 & Banco Español de Crédito \\
\hline
\end{tabular}

$\left({ }^{*}\right)$ Además de todas estas entidades, contaban con representante el Banco de Bilbao y el Banco Central.

Fuentes: Elaboración propia.

Consejo Superior de Ferrocarriles, Estatuto Ferroviario, Caja Ferroviaria y Dirección General de Ferrocarriles y Tranvías fueron las instituciones que diseñó el Estado para modificar las existentes desde 1855, mejorar el servicio y obligar a las empresas a mejorar su gestión y el cumplimiento del contrato. Pero resulta difícil hacer balance de los logros debido al carácter inacabado de su aplicación tras el precipitado final político del régimen dictatorial. Por ello es tarea compleja realizar una síntesis que caracterice esta etapa. Quizá el aspecto de reformas inconclusas sería una característica. Algo en lo que conviene insistir es que, por parte del gobierno, no hubo un objetivo claro y único de lo que quería hacerse con el sector y con las empresas, conforme pasaba el tiempo tras la aprobación del Estatuto ${ }^{48}$. Esas dudas se expresan en un comportamiento errático que, comprendiendo las fuertes necesidades de financiación de las constantes inversiones que requería el sector, se quedó a medio camino al no poder soportar el peso de la deuda contraída y haber cerrado otras posibles fuentes de financiación a las empresas. La Dictadura incrementó el patrimonio ferroviario público y permitió a los accionistas de las grandes percibir incertidumbre para buscar soluciones y nuevas dificultades a las empresas (Hernández Marco, 2002). Para Gómez Mendoza (1999), esta supuesta competencia tuvo mucho de argumento para la defensa de los intereses ferroviarios. 
dividendos superiores a los de otras épocas, pero no resolvió ningún asunto fundamental, a pesar de haber contribuido a modernizar el servicio. Se dejaba así un grave problema al régimen siguiente, pues no se arbitraron los mecanismos financieros que habrían permitido mantener el ritmo de amortizaciones y nuevas inversiones necesarias para garantizar la competitividad del sector.

\section{Un nuevo cambio institucional: la II República (1931-1936)}

El cambio de régimen político acontecido el 14 de abril de 1931 se tradujo en numerosas consecuencias para las empresas ferroviarias ${ }^{49}$. La Caja había sido suprimida mediante una nota oficiosa el 2 de julio de 1930, finalizando así sus actividades ${ }^{50}$. En teoría, al menos, el Estatuto había quedado escollado y se planteó, en el momento menos oportuno, el problema de la indefinición jurídica del sector. Además, el Estado debía pagar la deuda que había contraído y muchas de las obras iniciadas en la Dictadura se abandonaron o ralentizaron en la República por falta de recursos o por lo descabellado de los proyectos emprendidos, lo que puso en evidencia que la simplificación de Cambó para clarificar el problema era útil pero no respondía por completo a la realidad. Todas esas inversiones y proyectos sacaron a la luz muchos "problemas ferroviarios", tantos como empresas, y el grave problema estructural. La magnitud de los conflictos políticos que hubo de afrontar la República le impidió abordar con equilibrio, serenidad y tiempo suficiente los problemas que planteaba el ferrocarril: desde los financieros, los de la explotación de la red, los laborales, los derivados de la creciente competencia de la carretera; hasta el más grave de la definición jurídico-administrativa y económica del sector, que había dejado inconcluso la Dictadura ${ }^{51}$.

En toda esta etapa, las relaciones entre el Estado y las compañías fueron más tensas y conflictivas que en las anteriores. La obra legislativa de la Dictadura quedó en suspenso y la capacidad de actuación de los gobiernos sobre el sector muy coartada. Primero, porque la política ferroviaria de la Dictadura no había logrado dar término al marco regulador del sector, legando un gravísimo desequilibrio financiero.

49 Un estudio de las complicadas posiciones de gobiernos y compañías puede encontrarse en Ortúñez (1999), pp. 362-434.

Junta Superior de Ferrocarriles (1940), t. 2, p. 157. El texto decía: “Las compañías ferroviarias adscritas a la Caja Ferroviaria podrán continuar su obra de reparación y de mejora de sus líneas y material en la medida que lo estimen justo y razonable, sin contar con aportaciones del Estado".

51 Las dificultades fueron similares a las de los ferrocarriles de otros países, con los consecuentes desplomes en los resultados. Millward (2005), pp. 146-149. 
Y, segundo, porque debían ganarse el respaldo y apoyo de los trabajadores, y éstos a su vez consideraron que el nuevo régimen debía atender todas sus demandas. Las expectativas que a los ojos de los trabajadores abrió el triunfo de los partidos republicanos iban mucho más allá, empero, de lo que los gobiernos realmente podían y querían hacer. Los trabajadores se constituyeron, así, en un elemento clave en las relaciones entre las empresas y el Estado en estos años. Algunas de las medidas adoptadas, y que las empresas rechazaban, se explican, por ejemplo, desde la necesidad que tenía el Estado de contentar a los sindicatos para evitar huelgas.

El Consejo Superior de Ferrocarriles se convirtió en una de las expresiones más acabadas de esta conflictividad. Entre agosto de 1930 y marzo de 1936 se aprobaron un total de ocho disposiciones legislativas que disolvían, creaban, reorganizaban o modificaban su estatuto y funciones. Cinco de éstas tuvieron lugar entre abril de 1935 y marzo de 1936. No es posible detenerse por extenso en tantos pormenores; en realidad, se fue arrebatando lentamente representación a los concesionarios, en beneficio del Estado o de los trabajadores. Asimismo, al modificarse con tanta frecuencia su organización administrativa, creándose, suprimiéndose o fusionándose los distintos comités que lo configuraban, resulta difícil imaginar que aquello resultara mínimamente operativo al incrementarse, cuando menos, los costes de transacción. No existen fondos documentales del Consejo para estos años, lo que dificulta valorar su trabajo, pero a tenor de las cuentas de resultados de las empresas ${ }^{52}$ y de la ausencia de medidas por parte del Estado que profundizaran en la regulación del sector durante los treinta, puede concluirse que su labor no contribuyó en nada a la mejora de la actividad y que tal furor normativo obedeció más a espurios criterios políticos e ideológicos. Los efectos externos derivados de esta institución resultaron negativos para los agentes económicos.

Y ello aun cuando para los gobiernos de la República, y en particular los del primer bienio (1931-1933), "el problema ferroviario es el punto neurálgico, no ya del presupuesto parcial del Ministerio de Obras Públicas, sino de toda la obra económica general del gobierno" ${ }^{\prime \prime 3}$. El sentido que tenían estas palabras se correspondía con la gravedad del problema financiero heredado. El Estado no quería seguir sosteniendo líneas deficitarias, ni asumir la explotación de las mismas en caso de abandono por parte de sus concesionarios. Todo ello sin considerar que otras inversiones ferroviarias sí había que mantenerlas y que la situación de las empresas se agravó debido a la desaparición de la Caja y a la obtención de resultados negativos en la

52 Comín et al. (1998), pp. 361-367; y Ortúñez (1999), pp. 342-361.

53 Discurso de Prieto en defensa del proyecto del presupuesto del Ministerio de Obras Públicas, Diario de Sesiones de las Cortes, L-1932, núm. 137, 17 de marzo, pp. 4546-4553. 
explotación. La solución no era sencilla y, de hecho, no se llegó a ninguna ${ }^{54}$. El Estado, amparado en la importancia de las inversiones que había realizado hasta entonces, apretó más a las empresas y la intervención se estrechó. Pero no se alcanzó la aprobación de ninguna medida legislativa que paliara la crisis, y algunos intentos, como una nueva elevación de tarifas en mayo de 1934, tuvieron un período de vigencia insuficiente para que se apreciaran resultados - aunque lograron que, pese a la caída de los tráficos, se mantuvieran los ingresos-.

Se han visto en el apartado anterior los esfuerzos realizados por las empresas tendentes a constituir sus Consejos de Administración con personas vinculadas al sector financiero. Pues bien, en 1932 se aprobaron dos leyes importantes, una de ellas con incidencia sobre la estructura de propiedad de las empresas. La primera, del 10 de mayo, prescindiendo de otras leyes generales de ferrocarriles, permitía al Estado completa libertad para hacerse, o no, cargo de líneas abandonadas por alguna compañía. Si una empresa desatendía la explotación de alguna línea, la única solución que se establecía era la de declarar caducada la concesión. En ese momento se producía la reversión de la concesión al Estado, sin que al concesionario le correspondiese indemnización — con anterioridad a esta ley dictada por Prieto, el Estado se veía obligado a garantizar el servicio- ${ }^{55}$. Todo correcto y lógico para el Estado al ofrecerle libertad para decidir y permitirle no arrastrar cargas.

Situación más comprometida era la que se podía ocasionar con lo que regulaba la segunda, de 9 de septiembre de 1932, que creaba una intervención permanente del Estado en las compañías ferroviarias, justificada por su aportación al capital de las empresas. Esta intervención se llevó a cabo mediante los Comisarios, nombrados por el ministro de Obras Públicas y que contaban con derecho de veto suspensivo sobre las decisiones adoptadas por los organismos administradores de las compañías e, incluso, sobre la ejecución de acuerdos ya adoptados. Éste fue el procedimiento coercitivo que encontró el Estado para proteger sus intereses en las empresas. Las facultades concedidas al comisario le permitían bloquear la dirección de una compañía, hasta lograr, por ejemplo, que tuviese que solicitar la caducidad de una concesión. Esta misma ley, en el artículo $9^{\circ}$, prohibió que en los Consejos de Administración de las compañías hubiese personas que participasen de algún modo en empresas productoras de material para las compañías ferroviarias o que perteneciesen

54 Se intentaron cuatro proyectos de ordenación que se quedaron en diferentes etapas de su tramitación parlamentaria: Albornoz, Guerra del Río, Lucía (Marraco) y Velao.

55 La ley de 10 de mayo de 1932 forma parte de los hitos que explican el proceso de estatalización del régimen ferroviario. Expresa, además, la concepción de Prieto sobre el problema y la necesidad de cerrar la herida por la que se desangraba la economía española. Comín (1988), p. 1141. 
a más de tres Consejos de Administración ${ }^{56}$. El Estado recuperaba así, más que simbólicamente, el control sobre el sector: era capaz de fijar condiciones de pertenencia a los Consejos de Administración de una empresa concesionaria. A la postre esta decisión no supuso ninguna mejora en el funcionamiento del sistema, lo que puede permitir intuir su componente ideológico y político.

En definitiva, estas dos leyes podían llegar a conseguir la nacionalización sin coste para el Estado. Esto finalmente no sucedió, pero las bases se pusieron y las fricciones de las compañías con los comisarios fueron continuas. Todo ello cabría considerarlo como los típicos conflictos en cualquier sector regulado: un continuo tira y afloja entre el Estado y las compañías. Pero se fue más lejos de lo que se había ido hasta entonces. Algunos de los consejeros fueron obligados a renunciar a su cargo. Muchas de estas vacantes no se llegaron a cubrir después. La pérdida de valor de las ferroviarias fue una constante. Este proceso de vaciado de los sillones de los consejos reforzó, más aún, el papel del director general.

El antiguo Ministerio de Fomento tomó la nueva denominación de Obras Públicas, se le quitaron algunas de sus competencias, pero se le asignaron porcentajes del total de los presupuestos del Estado superiores a otros años. Los gobiernos de la República trataron de generar empleo mediante inversiones públicas; estas tendencias se apreciaron también en cuanto se refiere a los ferrocarriles. Las compañías continuaron percibiendo algunas cantidades del Estado, inferiores a las de años anteriores, aunque el sector recibió recursos procedentes de los presupuestos ordinarios y mayoritariamente destinados a inversiones intensivas en mano de obra ${ }^{57}$. Pero los diferentes gobiernos republicanos no tuvieron claro lo que querían hacer, ni con el sistema de transporte por ferrocarril, ni con las compañías, ni, sobre todo, cómo iban a hacerlo y con qué recursos. Sí parece evidente que compartían un afán grande por intervenir en las decisiones de las empresas, que ya venía de antes, y en no gastar recursos de un depauperado Estado que iban a destinarse tan sólo al beneficio de los capitales privados y a la resolución de sus conflictos, como acusaban a la Dictadura de haber realizado. La intervención estaba justificada, en su opinión, precisamente para poder garantizar y defender el capital público invertido en el sector. Para las compañías, en cambio, había sido el propio Estado el que, incumpliendo la legislación al no recorrer las etapas previstas en el Estatuto, había hecho que su situación

56 En esa situación se encontraban la mayor parte de los consejeros de las dos grandes empresas ferroviarias españolas. Para el texto de la ley de 9 de septiembre y el Decreto por el que se crearon cuatro comisarías, véase Junta Superior de Ferrocarriles (1940), t. III, pp. 30-32. El comisario de Norte denunció, por ejemplo, que algunos miembros del consejo de Norte y de MZA figuraban entre los miembros fundadores de la Compañía Nacional de Automotores, constituida el 1 de abril de 1935, por lo que una orden publicada el 8 de abril de 1936 les cesó de sus puestos en las ferroviarias. 
se hiciera cada vez más dependiente de unos recursos que no podían obtener ni del mercado, ni del desarrollo de su actividad.

\section{Conclusiones}

La organización y el gobierno de las grandes empresas ferroviarias españolas se vieron condicionados por los cambios políticos acaecidos entre 1918 y 1936. No podía ser de otra manera al tratarse de un servicio público desempeñado por empresas privadas y regulado por el Estado. En el trabajo se ha tratado de poner en relación los cambios institucionales acontecidos en España, y su reflejo en la política ferroviaria de cada gobierno, con las respuestas ofrecidas por las empresas para defender los intereses de los propietarios.

Los cambios en la estructura de propiedad de las ferroviarias españolas no fueron demasiado importantes. Con todo, se han mostrado varias tendencias que vinieron impuestas por el afán del Estado en recuperar el control del sector y se vieron facilitadas por los problemas económicos de las empresas: el refuerzo del sistema de gestión gerencial y la importancia del puesto de director general; el afán de los distintos gobiernos por evitar que los extranjeros controlasen ese servicio público; el esfuerzo de las empresas por profesionalizar y ampliar la presencia de banqueros en el Consejo de Administración; y la ampliación de la inversión pública y de las competencias ferroviarias del Ministerio de Fomento.

El Estado, por su parte, optó de manera decidida por intervenir en las compañías ferroviarias. Se habla de determinación, una voluntad firme de abordar la cuestión ferroviaria. Fue el Estado, de hecho, quien abrió el camino para efectuar una "re-regulación" que las compañías ferroviarias no querían, pues para éstas la libertad en el establecimiento de tarifas era suficiente. Se ha tratado de demostrar que eso es lo que se hizo de modo definitivo a partir de 1922, y que uno de los instrumentos empleados por el Estado que tuvo más permanencia en el tiempo fue el Consejo Superior de Ferrocarriles, creado por aquel entonces. El Consejo fue un instrumento de escasa utilidad, pero que refleja la motivación de los gobiernos a quienes servía. Así, la política de anticipos inaugurada en 1920, y el nacimiento y la pervivencia del Consejo Superior, el Estatuto ferroviario y sus consecuencias, muestran que la iniciativa y las decisiones correspondieron al Estado, que quiso resolver el problema de fondo y tomar directamente las decisiones encaminadas a ello. Pero las dificultades se multiplicaron por la inestabilidad del marco institucional; por la falta de capacidad y de medios para lograr ejecutar las disposiciones que el regulador había adoptado sobre esas instituciones y con las que debía influir en el comportamiento de los agentes; y por el fracaso de éstas al no diseñar incentivos adecuados, ni tampoco reducir la incertidumbre en el sector. 
Las instituciones y organizaciones surgidas nunca lograron una mejor explotación de la red por la vía de una mayor competencia en el sector; ni el desarrollo de las condiciones en que se realizaba el servicio; ni, por lo que de momento sabemos, un abaratamiento de los precios a los usuarios. Entonces, ¿cuál fue el problema que pretendió arreglar el Estado?, y ¿por qué no lo consiguió? Se han ofrecido diversas respuestas. El hecho de que, aparentemente al menos, sólo la Dictadura estuviese cerca de lograrlo al aumentar — aunque esto generase un grave desequilibrio a los gobiernos venideros - las inversiones destinadas al sector - mayoritariamente a las grandes empresas-, alumbra una posible respuesta a estas cuestiones. El problema que se pretendió resolver, con el fin de mejorar el servicio público, fue siempre el mismo: regular de nuevo el sector y definir en la nueva situación cómo se haría presente el Estado. Este modo de proceder se vio pronto que no servía y se optó por invertir los términos: mejorar la explotación financiando esas mejoras y así introducirse en las empresas. Pero estos objetivos en gran medida tampoco se alcanzaron a corto plazo, porque el marco institucional no logró crear las condiciones en las que el Estado y las empresas pudieran acertar en las elecciones dirigidas a estimular un comportamiento más cooperativo entre ellos. El sistema de incentivos fracasó. Además, lejos de conseguir la reducción de la incertidumbre entre los agentes, ésta se incrementó al mermar la confianza y generar más comportamientos oportunistas. El Estado sí logró liberarse, como efecto indirecto de la I Guerra Mundial, de la captura empresarial. Se ha podido mostrar, en algún caso con mayor evidencia, que, por parte del regulador, los factores ideológicos intervinieron en los procesos de elección $\mathrm{y}$ toma de decisiones.

\section{Bibliografía}

ANDERSSON-SKOG, Lena (2000): “National Patterns in the Regulation of Railways and Telephony in the Nordic Countries to 1950", Scandinavian Economic History Review, XLVIII, 2, pp. 30-47.

ANDERSSON-SKOG, Lena, y KRANTZ, Olle (1999) (eds.): Institutions in the Transport and Communications Industries: State and Private Actors in the Making of Institutionals Patterns, 1850-1990, Canton, Science History Publications.

ARTOLA, Miguel (1978): “La acción del Estado", en ARTOLA, Miguel (dir.), Los Ferrocarriles en España, 1844-1943, Madrid, Banco de España, vol. 1, pp. 339-453.

CABRERA, Mercedes, y DEL REY, Fernando (2002): El poder de los empresarios. Politica y Economía en la España Contemporánea (1875-2000), Madrid, Taurus.

CARON, François (1973): Histoire de l'exploitation d'un grand réseau. La Compagnie de chemin de fer du Nord, París, École Pratique des Hautes Études. 
CARON, François (2005): Histoire des chemins de fer en France, Tome 2: 1883-1937, París, Fayard.

CARRERAS, Albert (1999): “Los ferrocarriles en Europa: algunas perspectivas históricas", en MUÑOZ, Miguel; SANZ, Jesús, y VIDAL, Javier (eds.), Siglo y medio del ferrocarril en España, 1848-1998. Economía, Industria y Sociedad, Madrid, Fundación de los Ferrocarriles Españoles, pp. 33-53.

CARRERAS, Albert, y TAFUNELL, Xavier (1997): “Spain: big manufacturing firms between state and market, 1917-1990", en CHANDLER, Alfred; AMATORI, Franco; y HIKINO, Takashi (eds.), Big business and the wealth of nations, Cambridge, Cambridge University Press, pp. 277-304.

-(2005) (coords.): Estadísticas Históricas de España. Siglos XIX-XX, Bilbao, Fundación BBVA.

CASTAGNOLI, Adriana (2006): “El Estado y el ferrocarril. La nacionalización de la red italiana y los modelos europeos 1840-1905", Transportes, Servicios y Telecomunicaciones, 11, pp. 144-161.

CHICK, Martin (1994): "Nationalization, privatization and regulation”, en KIRBY, Maurice, y ROSE, Mary (eds.), Business Enterprise in Modern Britain. From the Eighteenth to the twentieth century, Londres, Routledge, pp. 315-338.

COMÍN, Francisco (1988): Hacienda y Economía en la España Contemporánea (18001936), Madrid, Instituto de Estudios Fiscales.

COMÍN, Francisco; MARTÍN, Pablo; MUÑOZ, Miguel; y VIDAL, Javier (1998): 150 Años de Historia de los Ferrocarriles Españoles, Madrid, Fundación de los Ferrocarriles Españoles.

GÓMEZ MENDOZA, Antonio (1999): "Motor Cars and Railways in Interwar Spain. Regulation vis-à-vis Deregulation", en ANDERSSON-SKOG, Lena, y KRANTZ, Olle (eds.), Institutions in the Transport and Communications Industries: State and Private Actors in the Making of Institutionals Patterns, 1850-1990, Canton, Science History Publications, pp. 199-215.

GOURVISH, Terence (1999): “The Regulation of Britain's Railways: Past, Present and Future", en ANDERSSON-SKOG, Lena, y KRANTZ, Olle (eds.), Institutions in the Transport and Communications Industries: State and Private Actors in the Making of Institutionals Patterns, 1850-1990, Canton, Science History Publications, pp. 117-132.

GREIF, Avner (2005): “Commitment, Coercion, and Markets: The Nature and Dynamics of Institutions Supporting Exchange", en MÉNARD, Claude, y SHIRLEY, Mary (eds.), Handbook of New Institutional Economics, The Netherlands, Springer, pp. 727-786.

-(2006): Institutions an the Path to the Modern Economy. Lessons from Medieval Trade, Cambridge, Cambridge University Press. 
GUILLÉN, Javier (2007) (dir.): El Régimen Jurídico del Sector Ferroviario. Comentarios a la Ley 39/2003, de 17 de noviembre, del Sector Ferroviario, Pamplona, ThomsonAranzadi.

HERNÁNDEZ MARCO, José Luis (2002): “Las primeras reacciones de las compañías ferroviarias españolas al inicio de la competencia automovilística antes de la guerra civil", Revista de Historia Económica, 2, pp. 335-363.

HERRANZ, Alfonso (2004): La dotación de infraestructuras en España, 1844-1935, Madrid, Banco de España.

JORDANA, Jacint, y RAMIÓ, Carles (2005): “Gobierno y Administración”, en CARRERAS, Albert, y TAFUNELL, Xavier (coords.), Estadísticas Históricas de España. Siglos XIX-XX, Bilbao, Fundación BBVA, pp. 973-1026.

JUNTA SUPERIOR de FERROCARRILES (1940): Antecedentes y Datos para el estudio del problema ferroviario, Madrid, Ministerio de Obras Públicas, 6 vols.

MAGNUSSON, Lars, y OTTOSSON, Jan (2001) (eds.): The State, Regulation and the Economy. An Historical Perspective, Cheltenham, Edward Elgar.

MARTORELL, Miguel (2000): El santo temor al déficit. Política y Hacienda en la Restauración, Madrid, Alianza.

MILLWARD, Robert (2005): Private and public enterprise in Europe. Energy, telecommunications and transport, 1830-1990, Cambridge, Cambridge University Press.

MUÑOZ, Miguel (1995): Renfe (1941-1991). Medio siglo de ferrocarril público, Madrid, Luna.

-(1999): "El Estado como empresario ferroviario", en MUÑOZ, Miguel; SANZ, Jesús; y VIDAL, Javier (eds.), Siglo y medio del ferrocarril en España, 1848-1998. Economía, Industria y Sociedad, Madrid, Fundación de los Ferrocarriles Españoles, pp. 299-336.

ORTÚÑEZ, Pedro Pablo (1998): “Ownership and control of Railway companies in Spain: a case study on the Madrid Zaragoza Alicante (MZA), 1913-1941", en ARMSTRONG, John; BOUNEAU, Christophe, y VIDAL, Javier (eds.), Railways management and its organisational structure, Madrid, XII International Economic History Congress, pp. 31-47.

-(1999): El proceso de nacionalización de los ferrocarriles en España,1913-1941, Tesis Doctoral inédita, Universidad de Valladolid.

—(2002): "Reducción de competencias, mantenimiento del gasto: 1914-1936", Transportes, Servicios y Telecomunicaciones, 2, pp. 96-147.

-(2004): "The nationalisation of companies with concessions in the Spanish Railway sector (c. 1900-1940)", Entreprises et Histoire, 37, pp. 75-87.

ORTÚÑEZ, Pedro Pablo, y VIDAL, Javier (2000): "State and private companies in the Spanish Railway sector, 1848-1941", en KUIJLAARS, Anne; PRUDON, Kim, y VISSER, Joop (eds.), Business and Society, Rotterdam, Centre of Business History, pp. 123-135. 
-(2004): “Régulation et intervention de l'État dans les sociétés ferroviaires en Espagne, (1830-1936)", en BOUNEAU, Christophe, y FERNÁNDEZ, Alexandre (eds.), L'entreprise publique en France et en Espagne. 18e-20e siècles, Bordeaux, Maison des Sciences de l'Homme d'Aquitaine, pp. 85-100.

PASCUAL, Pere (2000): “La gran decepción. La rentabilidad de las acciones de los ferrocarriles catalanes (1849-1943)", Revista de Historia Industrial, 17, pp. 11-59.

RAMOS, Rodolfo (2004): Reformas y políticas liberalizadoras del ferrocarril: El nuevo escenario en la Unión Europea, Madrid, Fundación de los Ferrocarriles Españoles.

TUSSELL, Javier, y GARCÍA QUEIPO DE LLANO, Genoveva (2001): Alfonso XIII. El rey polémico, Madrid, Taurus.

VIDAL, Javier (1996): “Las compañías ferroviarias y la difusión de las modernas formas de gestión empresarial en España, 1850-1914", en COMÍN, Francisco, y MARTÍN, Pablo (eds.), La Empresa en la Historia de España, Madrid, Civitas, pp. 285-301.

-(1999): “La estructura de la propiedad, de la organización y la gestión de una gran empresa ferroviaria: la Compañía de los Caminos de Hierro del Norte de España, 1858-1936", Revista de Historia Económica, 3, pp. 623-662.

VIDAL, Javier, y ORTÚÑEZ, Pedro Pablo (2002): "The Internationalisation of Ownership of the Spanish Railway Companies, 1858-1936", Business History, 44, 4, pp. 29-54. 